\title{
Rotina e Ordenação de Acontecimentos: um estudo sobre sequências temporais em livros didáticos de Matemática para o ciclo de alfabetização ${ }^{1}$
}

\author{
Julia Calheiros Cartela de Araujo \\ Professora do Instituto Capibaribe \\ juliacalheirospe@yahoo.com.br \\ Rosinalda Aurora de Melo Teles \\ Professora da Universidade Federal de Pernambuco \\ rosinaldateles@yahoo.com.br
}

\begin{abstract}
Resumo
Este artigo é um recorte de um estudo de mestrado em Educação Matemática que objetivou analisar a grandeza tempo em livros didáticos de matemática para o ciclo de Alfabetização. Para isso, analisaram-se atividades em 23 coleções aprovadas pelo PNLD 2013. Foram identificadas 1.256 atividades envolvendo tempo, dentre as quais, 86 tratavam a ideia de sequências temporais. Desta categoria, derivaram-se duas subcategorias: rotina e ordenação de acontecimentos. Os resultados mostram que a rotina é pouco abordada nas coleções. Predomina a ordenação de acontecimentos, representando $79 \%$ do total de atividades, apresentando o mesmo modelo das experiências de Piaget, a relação de "antes" e "depois".
\end{abstract}

Palavras-chave: Tempo; Livro didático; Sequências temporais; Ciclo de Alfabetização.

\section{Routine and Order of Events: a study on temporal sequences in mathematics textbooks for literacy cycle}

\begin{abstract}
This article is an excerpt from a study MSc in Mathematics Education which aimed to analyze the magnitude time math textbooks for the cycle Literacy. For this, we analyzed activities in 23 collections Literacy Mathematics textbooks approved by PNLD 2013. We identified 1,256 activities involving time, among which 86 dealt with the idea of temporal sequences. This category derived two subcategories: routine and ordering of events. The results show that the routine is somewhat addressed in collections. The order of events is more addressed, representing $79 \%$ of total activity, with the same model of Piaget's experiments, the ratio of "before" and "after."
\end{abstract}

Keywords: Time; Textbooks; Temporal Sequences; Cycle Literacy.

\section{Introdução}

Dentre as grandezas matemáticas, o tempo desperta um fascínio e interesse proporcional à dose de mistério que sempre carregou ao longo da história. Embora se apresente como uma das experiências mais elementares do homem comum, o tempo é uma

\footnotetext{
${ }^{1}$ Boletim Gepem (Online) ISSN: 2176-2988 | n. 64 - Jan./Jun. 2014 (texto em diagramação).
} 
das realidades conceituais mais complexas da história da humanidade e um dos enigmas do pensamento filosófico (GONZAGA, TENÓRIO E BASTOS, 2007).

É importante a comparação dos acontecimentos no tempo e a narração de histórias. É necessário ainda o estudo do ciclo vital dos seres vivos e a necessária compreensão da espacialidade e temporalidade dos fenômenos geográficos. Cada um destes aspectos ou fenômenos é estudado nas específicas áreas do conhecimento, a saber: História, Geografia, Ciências Naturais, Língua Portuguesa e Matemática, o que nos leva a crer que o tempo possui aspecto multidisciplinar, podendo ser olhado a partir de vários pontos de vista. No ensino e aprendizagem da Matemática, é incluído no bloco de conteúdos grandezas e medidas nos Parâmetros Curriculares Nacionais (PCN, BRASIL, 1997).

No cotidiano, as crianças têm experiências com as marcações do tempo (dia, noite, hoje, amanhã). De acordo com os PCN de Matemática (BRASIL, 1997), é importante que ao longo do ensino fundamental os alunos vivenciem diferentes situações que os levem a lidar com grandezas físicas, tais como a grandeza tempo. A pesquisa de mestrado Araujo (2013), analisou opções metodológicas e conceituais em relação ao tempo em livros didáticos do ciclo de alfabetização matemática. Neste recorte, especificamente, discute-se uma das categorias do estudo, sequências temporais, e suas subcategorias, rotina e ordenação de acontecimentos.

O Ciclo de Alfabetização, que abrange os três primeiros anos iniciais $\left(1^{\circ}, 2^{\circ}, 3^{\circ}\right.$ anos) do Ensino Fundamental, já é considerado pelo Ministério de Educação (MEC) uma realidade nacional, estando essa organização presente em $65 \%$ do território nacional. A implantação do Ciclo, segundo o MEC (BRASIL, 2012, p.18), é justificada pelos professores e gestores quando apontam que "estão diretamente relacionadas à meta-compromisso de alfabetizar / letrar todas as crianças do Brasil até seus 08 anos de idade (Meta 05 do PNE)”.

Um dos argumentos para focar o estudo no ciclo de alfabetização dá-se pelo fato de que, em seu livro A noção de tempo na criança, Piaget (2002, p.423) estuda as noções temporais e sua interpretação psicológica a partir de algumas experiências que fez com crianças entre 6 a 8 anos. $\mathrm{O}$ autor define que "o tempo constitui uma coordenação dos movimentos de diferentes velocidades: movimento do objeto para o tempo físico, ou movimento do sujeito para o tempo psicológico". Durante sua pesquisa, Piaget (2002) mostra que a construção dos estágios de inteligência (assim como os da noção de tempo) passa por uma série de movimentos, sejam eles reais ou ideais de geometria, o que caracteriza o sujeito epistêmico de sua pesquisa.

Um dos recursos utilizados na escola, que auxilia na proposição dessas situações, é o livro didático, que, algumas vezes, torna-se indispensável na sala de aula ou o único 
recurso para o professor. De acordo com Miranda e Luca (2004), a instituição de uma Comissão Nacional do Livro Didático aconteceu pela primeira vez durante o Estado Novo, tendo como consequências o estabelecimento de regras para a produção, compra e utilização do livro didático. A criação do Programa Nacional do Livro Didático (PNLD), em 1985, foi um marco na política em relação aos materiais didáticos.

Os livros didáticos, segundo Pavão (2011), devem favorecer o diálogo e o respeito. O autor também fala das possibilidades que o livro didático oferece ao aluno e ao professor, quando proporciona acesso a informações corretas e necessárias ao crescimento pessoal, intelectual e social. Observar como os livros didáticos desenvolvem determinados temas pode ajudar a pensar sobre os conhecimentos que são propostos aos alunos.

Neste artigo, discutimos a abordagem de atividades que envolvem sequências temporais em livros didáticos de matemática para o ciclo de alfabetização. Ou seja, que atendem aos $1^{\circ}, 2^{\circ}$ e $3^{\circ}$ anos do Ensino Fundamental. São atividades que exploram a relação do "antes" e "depois" em uma série temporal.

Ao assumirmos a perspectiva do tempo enquanto grandeza matemática, discutimos neste artigo, o tempo a partir de sua história, a ideia de duração e sucessão para a construção do seu conceito, e como grandeza relacionada à duração de intervalos de tempo.

\section{Tempo: escravo e senhor da história}

O tempo é um dos temas mais antigos e estudados. Os homens primitivos determinavam a contagem dele por meio das observações dos fenômenos naturais, como o dia e a noite e as variações das marés. No entanto, milênios antes de cristo, o ser humano começou a observar que as sombras das árvores e das pedras, projetadas pelo sol, moviamse e, pelo caminho percorrido por elas, era possível estabelecer um sistema de medida para passar o tempo (ZAMPIROLO, 2000, p.3).

Numa das primeiras tentativas de marcar o tempo, os Chineses cravaram uma estaca no solo, num lugar onde o sol batesse o dia todo. Observando o deslocamento da sombra da estaca, fizeram quatro riscos no solo, dividindo o dia em quatro partes iguais. Posteriormente, cada uma das quatro partes foi dividida em outras três, passando o dia a ter doze partes iguais (12 horas). Nesse passado bem remoto as atividades humanas estavam restritas aos períodos em que havia claridade. Dessa forma, só depois de muito tempo, 
estabeleceu-se que a noite também teria a duração de 12 horas, ficando o período entre um amanhecer e outro com 24 horas no total (ZAMPIROLO, 2000, p.3).

De acordo com Whitrow (1993), no Egito há registros da correlação entre os eventos naturais e sociais; tudo era decidido e feito a partir do rio Nilo, que tinha um ciclo aproximadamente regular. As cerimônias de coroações dos faraós estavam ligadas à história de Osíris, pois ela considerada uma divindade que representava a fertilidade.

Outra civilização que influenciou quanto à contribuição da construção do conceito de tempo foi a grega, sendo essa contribuição muito forte na questão filosófica. Whitrow (1993, p.49) fala sobre a marcação temporal dos gregos destacando que:

Além do gnômon, ou quadrante solar, e da clepsidra, ou relógio de água [...] do qual, em cerca de $270 \mathrm{aC}$, Ctesíbio de Alexandria inventou uma versão aperfeiçoada, com fluxo mais constante [...], há remanescentes de instrumentos mais elaborada como a Torre dos ventos.

A civilização romana destaca-se pela criação do calendário Juliano, que, após o ano 8 d.C., foi utilizado em todo mundo ocidental. Também foi nesse calendário que surgiu a ideia do ano bissexto.

Se pensarmos o tempo como grandeza, especificamente se utilizando das unidades de medida numa perspectiva histórica, conforme discutido acima, vários objetos de mensuração foram associados ao tempo, em função das eras e dos costumes humanos das respectivas épocas.

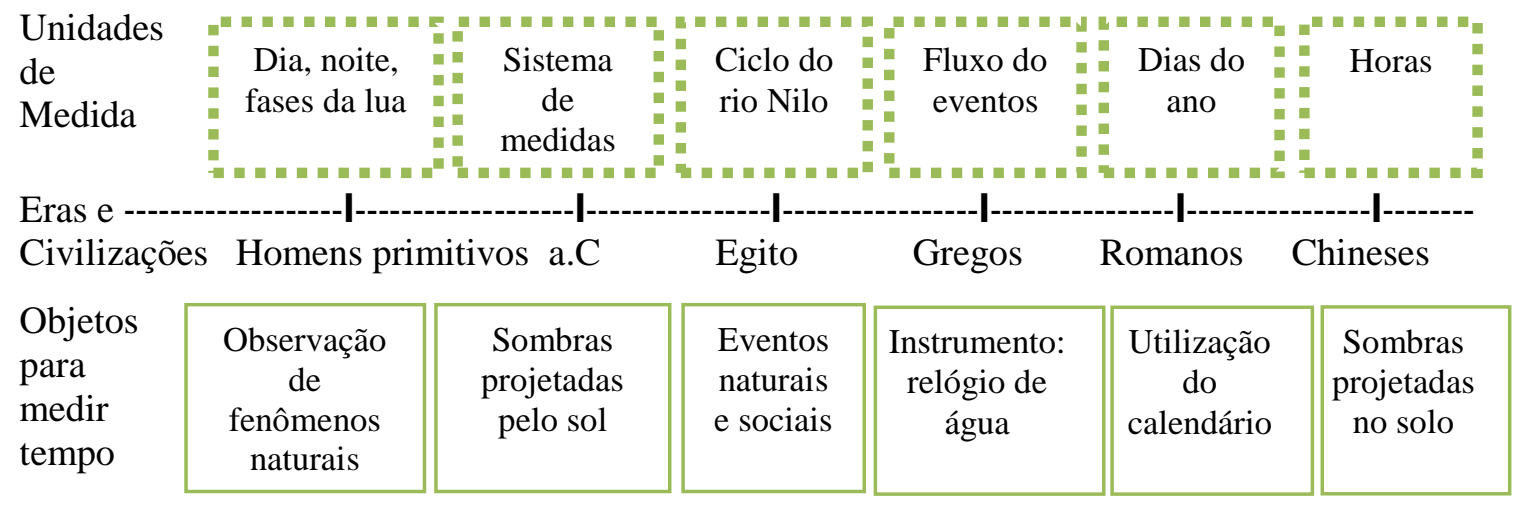

A partir dessa discussão sobre o tempo, numa perspectiva histórica, percebemos que desde a sociedade mais primitiva, a sua marcação já era um fato relevante na vida das pessoas, mesmo sendo feita, inicialmente, de forma mais rudimentar. Estabelecer um sistema de medidas de tempo foi um processo vivido e trabalhado por diferentes civilizações do mundo, na tentativa de marcá-lo de forma mais precisa. A discussão sobre tempo ainda é um tema atual, bastante debatido em várias áreas de conhecimento. Cada Ciência busca compreendê-lo de um modo peculiar e cada vez melhor, se isto for possível, pois o tempo é 
infinito, não para e, na verdade, rege com maestria, metaforicamente, nossas vidas, sendo ao mesmo tempo senhor e escravo da história.

\section{Tempo: duração e sucessão}

Em seus trabalhos sobre a noção de tempo, Piaget realizou estudos sobre a duração, sucessão dos acontecimentos percebidos e sobre a ideia de simultaneidade. O autor percebe que as crianças têm dificuldade de pensar o tempo (regência verbal) sob a forma de uma sequência linear e de representar os acontecimentos por uma série de imagens distintas que se seguem no espaço e não constituem, na realidade, senão uma só. Segundo Piaget (2002), a tradução da sucessão do tempo em uma sequência linear (unidimensional) não é uma coisa que se imponha por si, necessariamente, mas, ao contrário, pressupõe a unicidade do tempo, isto é, a possibilidade de ligar todas as relações de "antes" e de "depois" em uma única série temporal.

O enfoque de Piaget sobre a noção de tempo enfatiza a coordenação de movimentos: “o tempo é a coordenação operatória dos próprios movimentos, então as relações de simultaneidade, de sucessão e de duração deverão se constituir, todas, progressivamente, apoiando-se umas nas outras" (PIAGET, 2002, p.14).

Para o autor, o tempo passa de um intuitivo (ou psicológico) para um tempo operatório. O tempo intuitivo é a percepção gerada a partir da experiência empírica, onde não há reflexão sobre a ação, o que descaracteriza esta ação como uma operação. Já o tempo operatório é caracterizado pela presença da reversibilidade de pensamento, propiciando o desenvolvimento das relações de sucessão, simultaneidade e duração.

A noção de tempo também é investigada na narrativa infantil, como pode ser visto na dissertação de mestrado de Maria Inesila Montenegro Sauer, intitulada A constituição da narrativa infantil e suas relações com a construção das noções espaço-temporais $e$ causais, defendida em 2000. A pesquisa foi fundamentada na teoria de conhecimento de Jean Piaget, tendo como objetivo pesquisar as relações entre a estruturação da narrativa oral e a construção das noções de espaço, tempo e causalidade em 74 sujeitos de 4 a 8 anos de idade. Os resultados da pesquisa permitiram constatar uma significativa relação entre a constituição da narrativa e as noções espaço-temporais e causais, tanto implícitas na sequência temporal como nas provas piagetianas, indicando que altos índices das referidas 
noções correspondem a uma narrativa bem elaborada e baixos níveis determinam somente descrição de fatos e personagens.

De acordo com Sauer (2000, p.39), a estruturação do campo temporal preserva estreitas relações com a elaboração do espaço, do objeto e da causalidade. Isso ocorre segundo a autora porque "as séries temporais, não são possíveis de se exteriorizar em forma de comportamentos isolados".

\section{Tempo: aquele que precede à existência}

A física aborda questões que discutem o conceito de tempo e seu nascimento na sociedade. A ideia do nascimento do tempo foi fundamentada pelo físico e químico Ilya Prigogine, ganhador do Nobel de Química em 1977.

Em relação ao nascimento do tempo, o físico Ilya Prigogine escreveu um livro chamado de La Nascita del Tempo (O Nascimento do Tempo), no qual o autor defende a ideia que o tempo não nasceu com o nosso universo. Segundo ele, o tempo precede à existência, e poderá fazer nascer outros universos. Segundo Ilya (1988), o nascimento do nosso tempo não é, por conseguinte, o nascimento do tempo. Já no vazio flutuante o tempo preexistia em estado potencial.

Questões sobre o tempo são estudadas há muitos anos. Segundo Ilya (1988), há cerca de 2500 anos, Aristóteles já analisava o problema do tempo: observava que o tempo era a medida do movimento na perspectiva do antes e depois. E é isto o que fazemos ainda hoje, segundo o autor, quando medimos o tempo com relógios que têm um movimento periódico. Existe uma polêmica entre Einstein e Bergson em relação ao tempo. Bergson pensava que o tempo é essencial, enquanto tal, nunca científico, e Einstein pensava que o tempo era acessório. Ilya (1988) diz que é convencido que o tempo é objeto da ciência e por isso deve ser colocado no seu lugar na estrutura da ciência moderna.

Na dissertação de mestrado de Paulo Henrique de Souza, intitulada Tempo, Ciência, História e Educação: Um diálogo entre a cultura e o perfil epistemológico, defendida em 2008, é discutida a visão dos físicos e filósofos sobre o tema, trazendo as duas linhas de pensamento concorrentes quanto ao tempo: uma centrada no instante, defendida por Aristóteles e outra na duração, defendida por Bergson e Santo Agostinho. 
Souza (2008) explicita a ideia que o pensador Hesíodo tinha sobre a concepção do tempo, no entendimento que os acontecimentos eram cíclicos. Segundo Whitrow (1993, p. 53), Hesíodo tinha a compreensão de que:

seu poema baseava-se implicitamente no conceito de tempo, embora a palavra tempo de fato nunca apareça nele; seu principal propósito era dar conselhos com relação à regulação das atividades do ano, havendo dias específicos de bom e mau agouro, próprios ou impróprios para diferentes atividades. Em suma, o tempo era visto por Hesíodo como aspecto da ordenação moral do universo.

Outros pensadores, como Heráclito e Anaximandro, compartilhavam a ideia do tempo como juiz. Anaximandro fez referência à justiça feita pelo tempo. Já Heráclito, de acordo com Whitrow (1993), acreditava que o mundo era formado por opostos, por exemplo, quente e frio. E ele acreditava num princípio que governava essas relações, representado pelo equilíbrio desses opostos, tendo o tempo como o juiz desse equilíbrio.

Já Parmênides diz que vivemos num mundo imutável e atemporal. Whitrow (1993, p.55) traz o pensamento de Parmênides em relação ao tempo, como ele sendo um contínuo "A partir disto, afirmava que, uma vez somente o presente é, disto decorre que o passado e futuro são igualmente carentes de significado [...] o único tempo presente contínuo, e o que existe é não criado e também imperecível".

Segundo Souza (2008, p.61), Platão (séc. IV a.C.) também discutiu o conceito de tempo, escrevendo uma obra cosmológica chamada $O$ Timeu, na qual "ele propõe que o espaço existe como uma estrutura estabelecida, em que o universo é moldado por formas geométricas eternas e em estado de repouso, ou seja, um universo ideal”.

Se pensarmos o tempo na noção de instante e duração, na perspectiva física, conseguimos relacionar vários pensamentos de filósofos e físicos associados ao tempo, como pode ser percebido no quadro 1.

Quadro 1. Pensamentos e ideias sobre o tempo

\begin{tabular}{|l|l|}
\hline \multicolumn{1}{|c|}{ Pensador } & \multicolumn{1}{c|}{ Suas ideias sobre o tempo } \\
\hline Aristóteles & Perspectiva do antes e depois, centrado no instante \\
\hline Bérgson & Tempo é essencial, ideia de duração \\
\hline Einstein & Tempo é acessório \\
\hline Hesíodo & Tempo como aspecto da ordenação moral do universo \\
\hline Anaximandro & Justiça feita pelo tempo \\
\hline Heráclito & Tempo juiz do equilíbrio dos opostos \\
\hline Parmênides & Tempo contínuo \\
\hline Platão & Universo em estado de repouso \\
\hline
\end{tabular}




\section{Tempo: uma grandeza matemática?}

Neste artigo abordamos a ideia de intervalos de tempo como grandeza. Uma definição de tempo como grandeza está presente no documento Referencial Curricular Nacional para Educação Infantil (RCNEI, BRASIL, 1998 p. 227), quando diz:

O tempo é grandeza mensurável que requer mais do que comparação entre dois objetos e exige relações de outra natureza. Ou seja, utiliza-se de pontos de referência e do encadeamento de várias relações, como o dia e noite; manhã, tarde e noite, os dias da semana; os meses; o ano etc. Presente, passado e futuro; antes, agora e depois são noções que auxiliam a estruturação do pensamento.

A definição do documento remete à ideia de intervalos de tempo ao afirmar que para medir o tempo é necessário estabelecer relações de outra natureza, utilizando-se de ponto de referência com a conexão de várias relações, sendo citado o exemplo dias da semana. Essa será a ideia abordada na nossa pesquisa, ou seja, especificamente em relação à duração de intervalos de tempo, admitir que há fenômenos periódicos na natureza para um observador na Terra, desde os astronômicos até os que ocorrem no micromundo dos átomos ou moléculas.

A ideia de intervalos de tempo compreende-se, por exemplo, quando escolhemos arbitrariamente um desses "relógios naturais" e neles certos objetos repetem sua posição em intervalos de tempo de duração aproximadamente igual, denominados períodos. No modelo abstrato para tal relógio, podemos admitir que tais durações são rigorosamente iguais e assim haverá um período T associado a tal relógio. Esta duração será uma unidade de duração de intervalos de tempo.

De posse desse "relógio natural" e do seu período T, podemos medir a duração de um evento que decorra em um dado intervalo de tempo. A medida da duração do evento será dada por "quantas vezes" a unidade T ocorre no decorrer do evento. Tal medida, abstratamente, pode ser um número real positivo qualquer. No mundo físico será sempre um número racional e será afetada pela incerteza inerente a toda medição empírica. A grandeza duração, no referido evento, será representada pela medida obtida por meio daquele "relógio natural", acrescida da unidade T: 2T, 4,5T, etc.

Diferentes relógios podem fornecer diferentes representações de uma mesma duração. $\mathrm{O}$ conhecimento da medida de um período $\mathrm{T}$, tomando como unidade outro período U, permite fazer a conversão entre essas representações. Trata-se do mesmo caso que ocorre com as demais grandezas mensuráveis. 
A partir dessa discussão teórica sobre o tempo, vamos analisar atividades que abordam a noção de sequência temporal, ou seja, a ideia de relacionar o "antes' e "depois" em uma série temporal, evolvendo as subcategorias rotina e ordenação de acontecimentos. Essa análise se fundamenta, principalmente, na discussão teórica da noção de tempo em estudos de psicologia apoiados em Piaget (2002).

\section{Procedimentos Metodológicos}

Tendo em vista que o foco da pesquisa são os anos iniciais do Ensino Fundamental, foram analisadas atividades que abordam a temática tempo em vinte e três coleções aprovadas pelo Programa Nacional do Livro Didático (PNLD) 2013, que fazem parte da alfabetização matemática ( $1^{\circ}, 2^{\circ}$ e $3^{\circ}$ ano). As coleções analisadas são compostas por três volumes, sendo um para cada ano de ensino, tendo como público alvo crianças com cerca de 6 a 8 anos de idade. As atividades que abordam a grandeza tempo foram analisadas e classificadas a partir das categorias, sintetizadas no esquema abaixo.

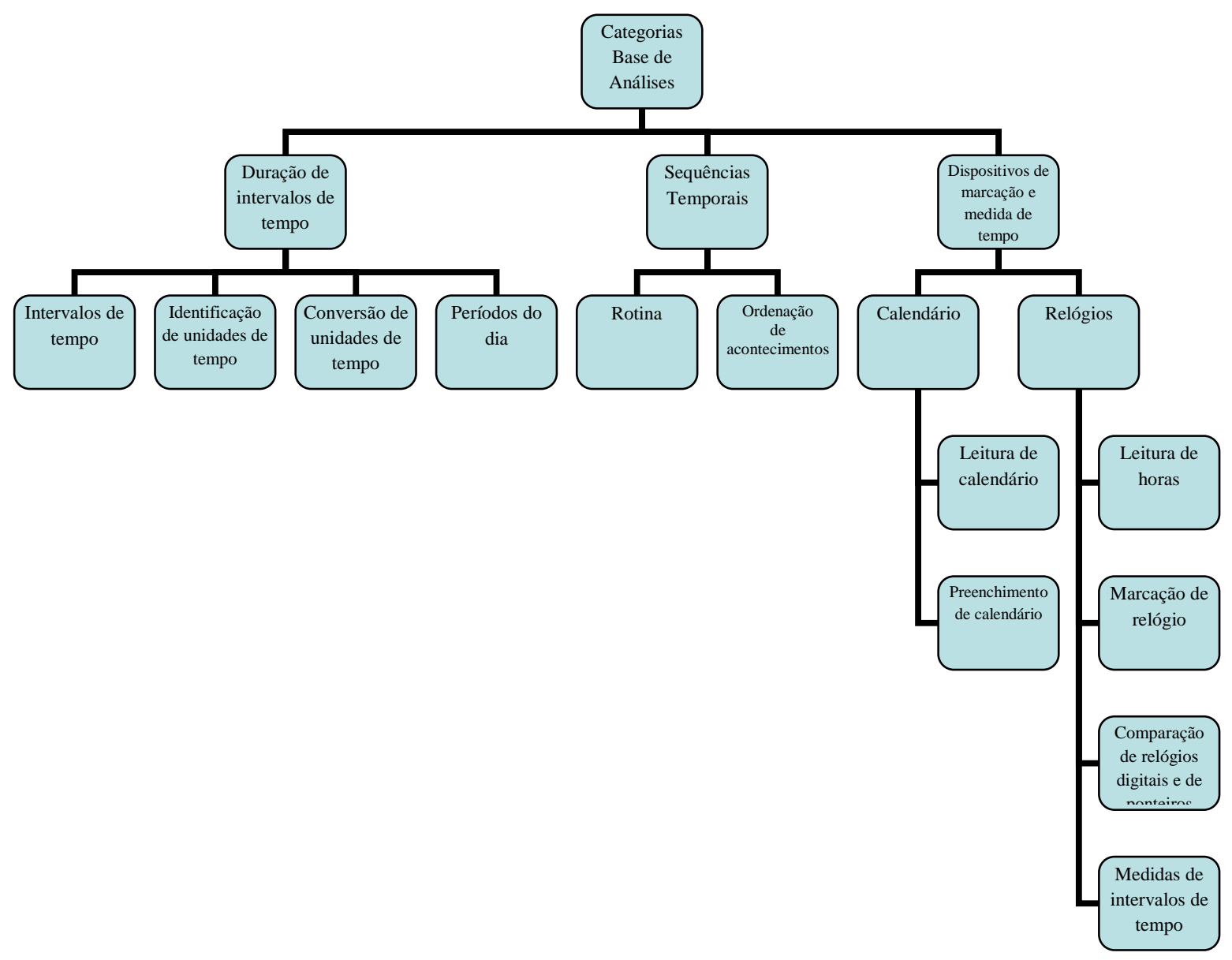


Para este artigo, fizemos um recorte no mapeamento e análise das atividades que abordam a categoria de sequências temporais e suas subcategorias: rotina e ordenação de acontecimentos, em todas as 23 coleções da alfabetização matemática aprovadas no PNLD 2013.

\section{Categoria sequências temporais}

Na primeira subcategoria, chamada rotina, classificamos atividades que trabalham o ritmo diário dos alunos e suas atividades. A segunda subcategoria é ordenação de acontecimentos, que foi baseada nos estudos Piaget sobre sequência linear dos acontecimentos. A seguir, apresentamos uma tabela com número de atividades dessa categoria por ano de ensino nas coleções analisadas.

Tabela 1. Atividades da categoria sequências temporais

\begin{tabular}{|l|c|c|c|c|}
\hline \multirow{2}{*}{ Sub Categorias } & \multicolumn{3}{|c|}{ Volumes da coleção } & \multirow{2}{*}{ Total } \\
\cline { 2 - 4 } & $1^{\mathbf{0}}$ ano & $2^{\mathbf{o}}$ ano & $3^{\mathbf{o}}$ ano & \\
\hline 1.Rotina & 3 & 10 & 5 & 18 \\
\hline 2 Ordenação de acontecimentos & 39 & 21 & 8 & 68 \\
\hline Total & 42 & 31 & 13 & 86 \\
\hline
\end{tabular}

Observando a tabela, percebe-se que a subcategoria ordenação de acontecimentos foi a mais presente no $1^{\circ}$ e $2^{\circ}$ ano de ensino. Essa subcategoria também é pouco abordada nos livros do $3^{\circ}$ ano. Já a subcategoria a rotina foi a que apresentou uma menor quantidade de atividades, somando 18 no total, porém as duas subcategorias apresentaram um quantitativo menor nos volumes do $3^{\circ}$ ano.

\section{Subcategoria rotina}

Identificamos nas 23 coleções um total de 18 atividades dessa subcategoria, no entanto dez coleções não abordaram nenhuma atividade. Esse dado mostra que a rotina é pouco trabalhada nos livros didáticos, embora atividades como estas possam contribuir para compreensão dos alunos em relação à organização do seu dia a dia.

Encontramos nas coleções dois tipos de rotinas:

- Rotina doméstica: quando o aluno registra suas atividades diárias.

- Rotina escolar: quando é solicitado o registro das atividades escolares. 
Nos três anos de ensino, identificamos dezesseis atividades do tipo rotina doméstica e duas atividades de rotina escolar.

Gráfico 1. Quantitativo dos tipos da subcategoria rotina

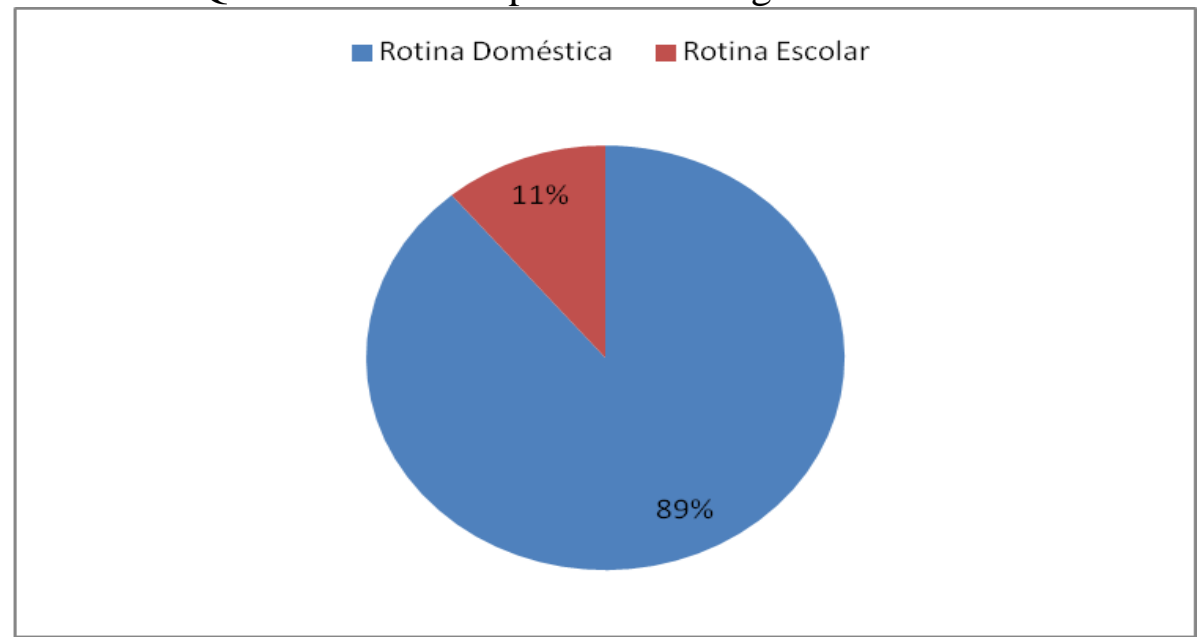

Observando o gráfico 1, percebe-se que predomina nos livros didáticos a rotina do tipo doméstica, represento $89 \%$ do total das atividades dessa subcategoria. As atividades classificadas nesse tipo são as que abordam a rotina diária dos alunos, como os horários de tomar café, almoçar, jantar. No exemplo a seguir, apresentamos um modelo de atividade do tipo rotina doméstica.

COMO VOCÊ USA SEU TEMPO?

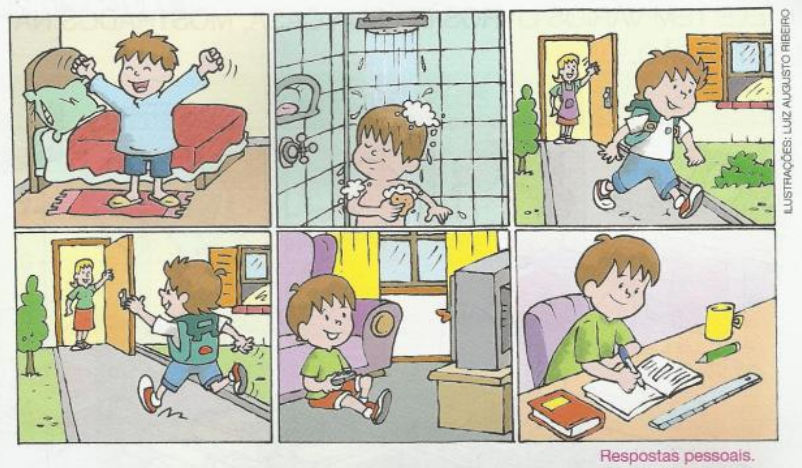

1. MARQUE O HORÁRIO EM QUE VOCÊ COSTUMA:

\begin{tabular}{|l|l|}
\hline LEVANTAR & \\
\hline TOMAR BANHO & \\
\hline IRÀ ESCOLA & \\
\hline VOLTAR DA ESCOLA & \\
\hline ASSISTIR À TELEVISÃO & \\
\hline ESTUDARE FAZER SUAS LÇÕES & \\
\hline
\end{tabular}

Figura 1. Atividade do tipo rotina doméstica

FONTE: Projeto Buriti/ Mara Regina Garcia Gay. $2^{\circ}$ ed.Editora Moderna, 2011, $1^{\circ}$ ano, p.25. 
Nos livros do primeiro ano, foram encontradas 3 atividades de rotina, sendo duas do tipo rotina doméstica, nas quais os registros dos horários das atividades são feitos utilizando as unidades de tempo; e uma, do tipo rotina escolar, no qual os registros das atividades escolares são feitos a partir de desenhos. Com essa análise, percebemos que os livros apresentam diferentes formas de representação para o aluno registrar suas atividades. No exemplo a seguir, apresentamos uma atividade do tipo rotina escolar, que solicita aos alunos o registro através de desenhos, sendo interessante esse tipo de atividade, pois é de um livro didático do $1^{\circ}$ ano, cujos alunos ainda estão se apropriando da escrita.

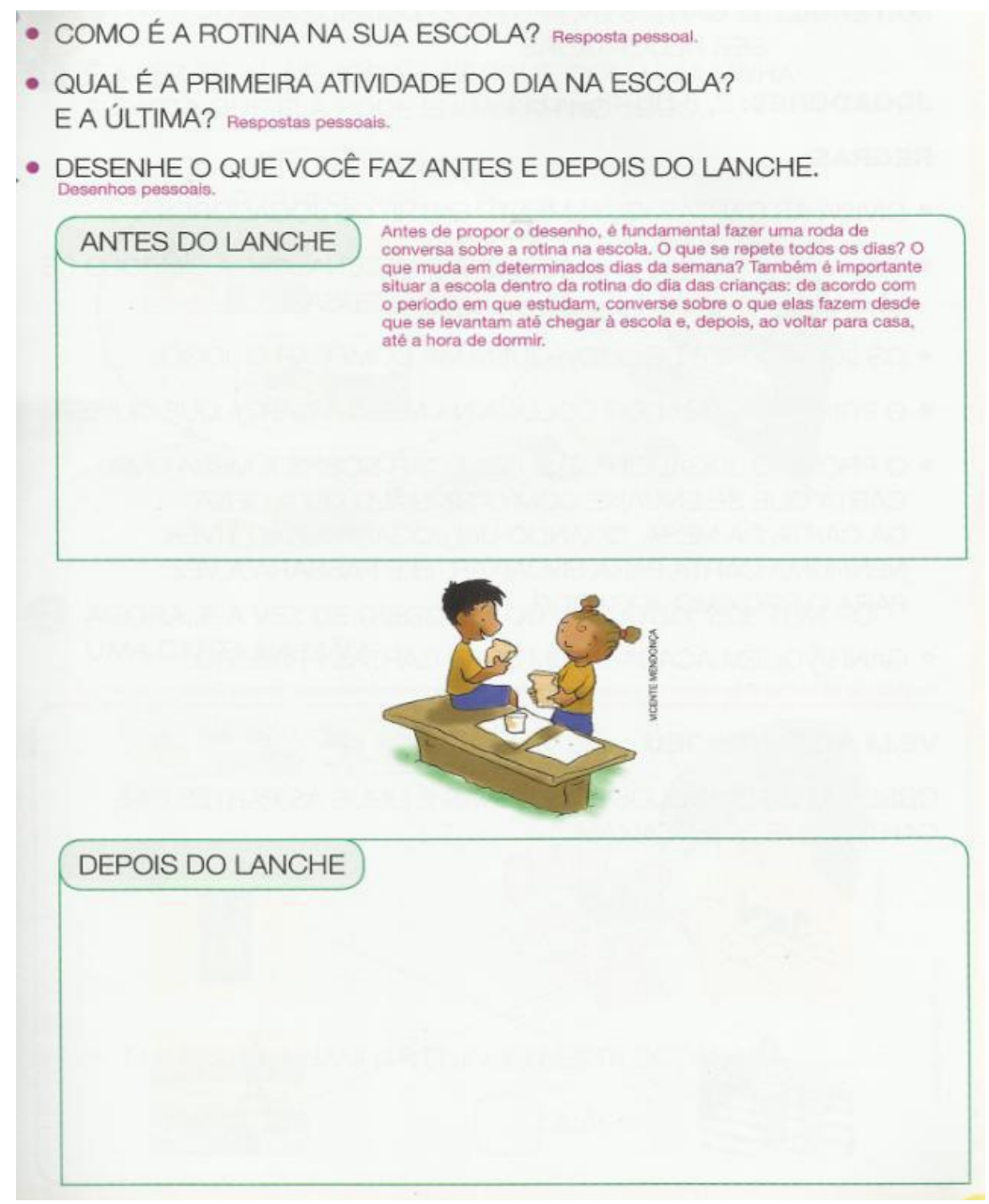

Figura 2. Atividade tipo rotina escolar

FONTE: Nosso Livro de Matemática / Célia Maria Carolino Pires, Ivan Cruz Rodrigues. $1^{\circ} \mathrm{ed}$. Editora Zapt Editora, 2011, $1^{\circ}$ ano, p.87.

O exercício da Figura 2 aborda as atividades que são feitas na escola. Esse exemplo se alinha com o documento RCNEI ( BRASIL, 1998), quando fala sobre a rotina utilizando o tempo didático, que seria o tempo de trabalho educativo que o professor tem para realizar atividades com seus alunos. 
No segundo ano, identificamos nos livros didáticos analisados, 10 atividades da subcategoria rotina, porém todas são do tipo rotina doméstica, com o registro da rotina, geralmente em quadros ou na linha, mediante as unidades de tempo. Nos livros do terceiro ano, identificamos 5 atividades, sendo todas do tipo rotina doméstica, o que se verifica no exemplo a seguir.

\section{A que horas você costuma: Professor: As respostas das atividades}
a. acordar?
b. almoçar?
c. jantar?
d. ir para a escola?
e. dormir?

Figura 3. Atividade do $3^{\circ}$ ano do tipo rotina doméstica

FONTE: Hoje é Dia de Matemática/Carla Cristina Tosatto, Claúdia Miriam Tosatto, Edilaine do Pilar F. Perachi. $2^{\circ}$ ed. Editora Positivo, 2011, $3^{\circ}$ ano, p.104.

Esse tipo de atividade é indicado pelo o RCNEI (BRASIL, 1998), quando este documento afirma a rotina pode ser facilitadora dos processos de desenvolvimento e aprendizagem. O documento ainda a considera como "um instrumento de dinamização da aprendizagem, facilitador das percepções infantis sobre tempo e o espaço, uma rotina clara e compreensível para as crianças é fator de segurança” (p.73).

\section{Subcategoria ordenação de acontecimentos}

Identificamos nas coleções um total de 68 atividades, porém cinco coleções não abordaram essa subcategoria em nenhum ano de escolaridade. Esse dado nos faz refletir que essa habilidade de ordenar em sequência temporal não é exercitada em algumas coleções, embora esta noção ajude na construção e compreensão do conceito de tempo, de acordo com o a orientação do documento curricular RCNEI (BRASIL, 1998), quando indica trabalhar com os alunos a ideia do "antes" e "depois". Nos livros do primeiro ano, encontramos 39 atividades, sendo mais da metade do total dos três anos de ensino. Já no segundo ano, tivemos 21 atividades dessa subcategoria; no terceiro ano, um quantitativo de 8 atividades. 
Gráfico 2. Quantitativo de atividades da subcategoria ordenação de acontecimentos

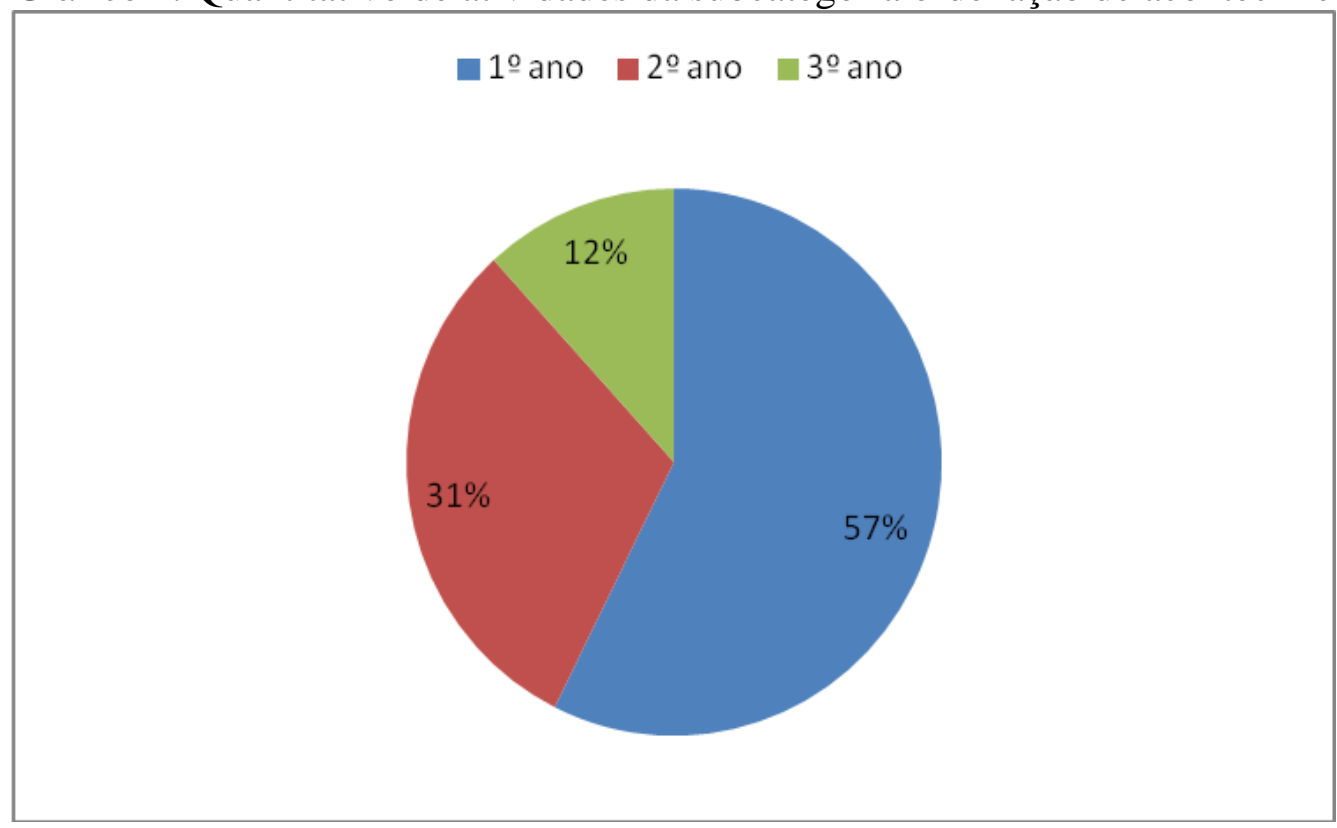

As atividades que classificamos como ordenação dos acontecimentos, geralmente, apresentam a mesma estrutura: imagens são postas fora da ordem e é solicitado aos alunos que enumerem ou coloquem na ordem os acontecimentos, como no exemplo a seguir.

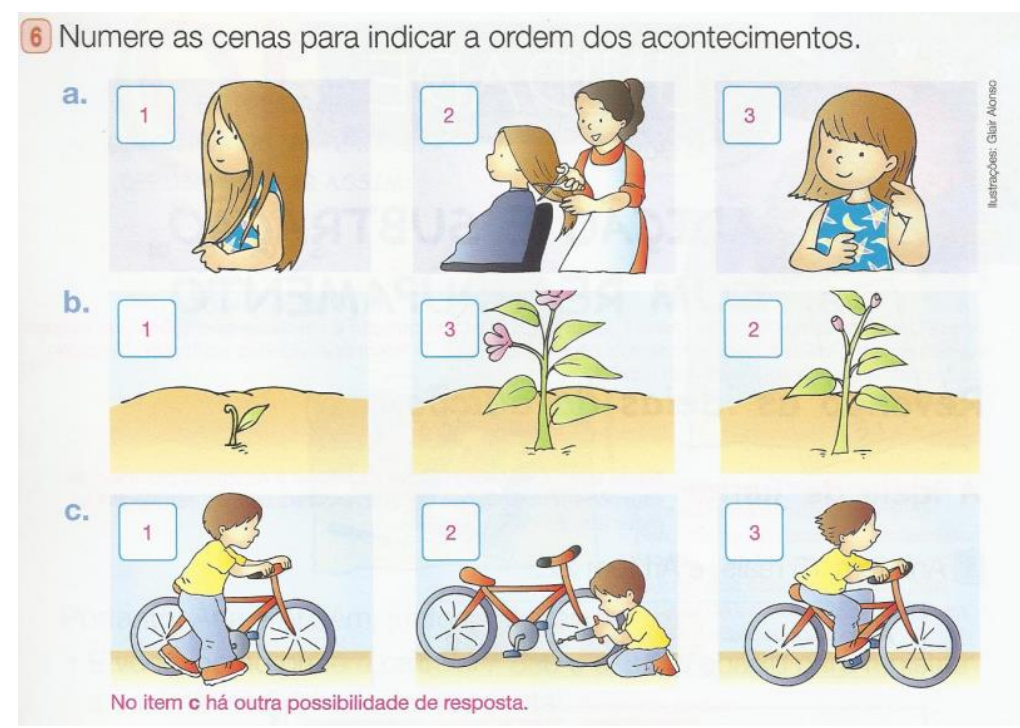

Figura 4. Atividade de ordenação dos acontecimentos

FONTE: Porta Aberta / Arnaldo Rodrigues, Junia La Scala, Marília Centurión. $1^{\circ}$ ed. Editora FTD, 2011, $2^{\circ}$ ano, p.167.

Esse tipo de atividade, Piaget (2002) comenta em seu livro "A noção de tempo na criança”, que escrevera um artigo em 1925, no qual crianças eram solicitadas a ordenar as “imagens em desordem" para reconstituir uma história. Piaget (2002, p.41) fala que as crianças estudadas nesse artigo e no livro "não conseguem seriar os desenhos conforme uma direção de conjunto por falta de mobilidade na elaboração das relações em pormenor". 
Ou seja, Piaget, desde 1925, já trabalhava com as crianças situações que elas teriam que organizar as imagens de acordo com a ordem dos acontecimentos.

\section{Conclusões}

Esta pesquisa teve como objetivo analisar atividades de livros didáticos da Alfabetização Matemática aprovadas pelo PLND 2013, que abordam a grandeza tempo relacionada à ideia de sequências temporais, da qual se derivam duas subcategorias: rotina e ordenação de acontecimentos.

Em síntese, os dados indicam que a subcategoria rotina é pouco trabalhada nos livros didáticos, porém identificamos que, dentre as atividades dessa subcategoria, rotina doméstica e rotina escolar, a doméstica é mais abordada pelos livros didáticos, abordando as atividades que os alunos fazem em casa no seu dia-dia. Outro aspecto percebido durante a análise foi o registro das atividades da rotina, sendo propostas pelas coleções diferentes maneiras de fazê-lo, como por exemplo, por meio de desenhos.

A segunda subcategoria, ordenação de acontecimentos, foi a mais abordada da categoria, com 68 atividades, representando $79 \%$ em relação ao total de 86 , sendo o volume do primeiro ano o que mais apresenta esse tipo de atividade, prevalecendo o modelo de organização de imagens em desordem que foram abordados nos estudos de Piaget.

Este estudo exploratório teve como foco apenas a abordagem do tempo em livros didáticos de matemática, no entanto acreditamos que outras pesquisas que envolvam, por exemplo, análises diagnósticas, numa perspectiva cognitiva sobre a construção da noção de tempo pelas crianças, ou análise de escolhas metodológicas dos professores em suas práticas, são necessárias para se constituir um corpo de conhecimentos sólidos sobre o ensino e a aprendizagem da grandeza tempo, ou simplesmente sobre o "tempo", tema multifacetado e multidisciplinar e, inegavelmente, presente em nossas vidas.

\section{Referências}

ARAUJO, J. C. C. Tempo, desafio conceitual e didático: um estudo exploratório sobre orientações dos documentos curriculares e atividades de livros didáticos para alfabetização matemática. $144 \mathrm{f}$. Dissertação (Mestrado em Educação Matemática e Tecnológica) - Universidade Federal de Pernambuco, Recife, 2013. 
BRASIL. Ministério da Educação e do Desporto. Secretária de Educação Fundamental. Parâmetros curriculares nacionais: matemática ( $1^{\mathrm{a}}$ a $4^{\mathrm{a}}$ série). Brasília: $\mathrm{MEC} / \mathrm{SEF}$, 1997.

. Ministério da Educação e do Desporto. Secretaria de Educação Fundamental.

Referencial Curricular Nacional para a Educação Infantil. Brasília: MEC/SEF. vol.3. 1998.

Ministério da Educação Conselho Nacional de Educação Câmara de Educação

Básica. Elementos Conceituais e Metodológicos para definição dos direitos de aprendizagem e desenvolvimento do Ciclo Alfabetização $\left(1^{\circ}, 2^{\circ}\right.$ e $3^{\circ}$ anos) do Ensino Fundamental. Brasília: MEC. 2012.

GONZAGA, Adahir ; TENÓRIO, Alexandre; BASTOS, Heloisa. O perfil epistemológico do conceito de tempo a partir de sua representação social. Ensaio Pesquisa em Educação em Ciências. vol.9.núm.2.2007.

PAVÃO, Antonio C. A série "livro didático em questão". disponível em <http://tvbrasil.org.br/fotos/salto/series/161240LivroDidatico.pdf $>$. Acesso em: 01 fev.2012. 2011.

PIAGET, J. A noção de tempo na criança. Rio de Janeiro: Record, 2002.

RODRIGUES, Márcia Cristina P. O ensino-aprendizagem em dança na construção das noções de espaço e tempo. (Dissertação de Mestrado) - Programa de Pós-graduação em Educação da UFRGS. Porto Alegre: UFRGS, 2007.

SAUER, Maria Inesila M. A constituição da narrativa infantil e suas relações com a construção das noções de espaço - temporais e causais. (Dissertação de Mestrado) Universidade Estadual de Campinas, Faculdade de Educação. Campinas: UNICAMP, 2000 .

WHITROW, G.J. O tempo na história: concepções do tempo da pré-história aos nossos dias. Rio de Janeiro: Jorge Zahar. 1993.

ZAMPIROLO, M, J,C,V. Olhando para o céu. Módulo de Matemática - Na dança das horas. PEC - Projeto Escola e Cidadania. São Paulo: Editora do Brasil, 2000.p.3. 